\title{
CANADIAN ANAESTHETISTS' SOCIETY ANNUAL MEETING SCIENTIFIC PROGRAMME
}

CHATEAU FRONTENAC, QUÉBEC, P.Q., JUNE 27 TO JULY 2, 1971

Monday, June 28

0845-0900 hours $0900-0930$

Opening remarks

CHAIRMAN: DR. S. L. VANDEWATER

"Intrauterine Foetal Lidocaine Concentrations during Epidural Anaesthesia"

G. S. Fox, G. L. Houle, P. D. Desjardins, and G. Mercier

$0930-1000$

$1230-1400$

"Transmission of Carbonated Lidocaine Across the Placenta during Caesarean Section"

$1000-1015$

G. L. Houle, G. S. Fox, and I. M. G. Torkington

1015-1030

Discussion

1030-1230

$1400-1430$

$1430-1500$

Coffee

Panel: "Medical Legal Aspects of Anaesthesia"

Chairman: Dr. S. L. Vandewater

Members: Dr. E. B. Tovee

Dr. C. Wasmuth

Mr. D. K. Laidlaw, Q.c.

Dr. T. L. Fisher

Lunch

"Serum Potassium Changes following Succinylcholine in Swine with Thermal Trauma or Sciatic Nerve Division"

G. A. Gronert and R. A. Theye

$1430-1500$

$1500-1515$

$1515-1530$

1530-1600

$1600-1630$

1630-1645

Tuesday, June 29

0830-0900 hours "General Anaesthesia in 8 Patients with Familial Dysautonomia"

H. Meridy and R. E. Creighton 


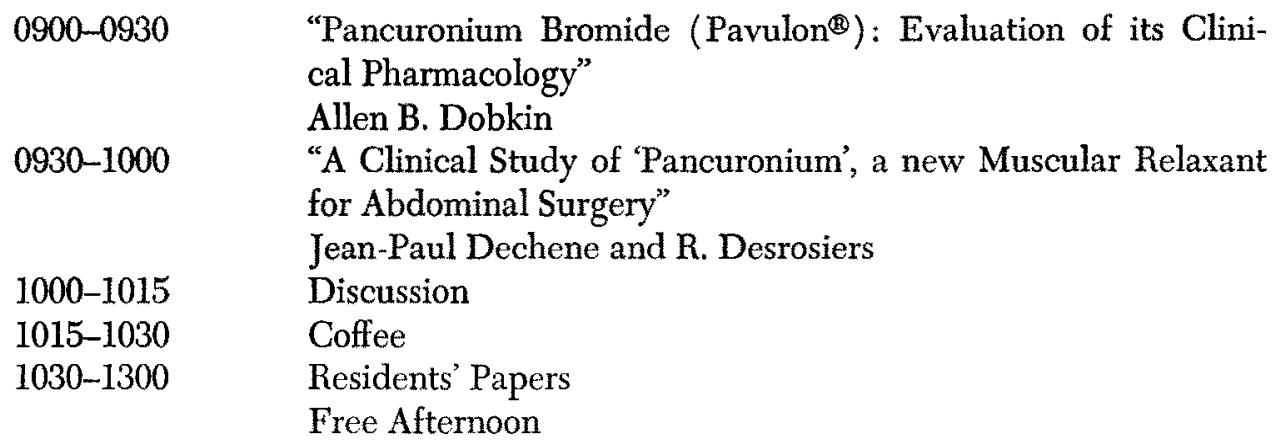

Wednesday, June 30

CHAIRMAN: DR. A. W. CONN

0900-1000 hours Guest Lecturer: Dr. Leroy D. Vandam,

Professor of Anaesthesia,

Harvard Medical School,

Director of Anaesthesia,

Peter Bent Brigham Hospital,

Boston, Mass.

1000-1015

Title: "Drug Interactions in Anaesthetic Practice"

$1015-1030$

Discussion

$1030-1230$

Coffee

$1230-1400$

Business Meeting

Lunch

$1400-1430$

CHAIRMAN: DR. J. P. DECHENE

"Hyperbaric Treatment of Cerebral Air Embolism, A Report of a Case Following Cardiac Catheterisation"

$1430-1500$

R. K. Calverley, W. A. Dodds, W. G. Trapp, and L. C. Jenkins "A Case of Therapeutic Lung Lavage for Alveolar Proteinosis"

G. A. Benazere and R. Desrosiers

$1500-1515$

Discussion

$1515-1530$

Coffee

$1530-1600$

"High Output Renal Failure following Methoxyflurane (Penthrane $\left.{ }^{(1)}\right)$ Anaesthesia in the Dog"

S. Stubbs, H. Fung, J. Wade, and A. E. Thomson

$1600-1630$

"Anaesthesia for simultaneous bilateral Nephrectomy"

$1630-1645$

L. C. Jenkins

Discussion

Thursday, July 1

0830-0930 hours

CHAIRMAN: DR. A. DRYSDALE

"General Anaesthesia for Pacemaker Implantation"

Andre McClish 
0900-0930

0930-1000

1000-1015

1015-1030

1030-1100

$1100-1130$

$1130-1145$

"Airway Closure and Alveolar Arterial Oxygen Differences in Man"

J. Couture, W. M. Wahba, E. Honsley, D. Craig, H. Don, M. Becklake, and J. Milic-Enuli

"Cardio-respiratory responses to severe hypoxaemia in anesthetised dogs"

H. I. A. Nisbet, P. M. Olley, I. G. Grey, and A. E. Johnston

Discussion

Coffee

"Effects of Volatile Anaesthetic Agents on EEG Activity Recorded in Limbic and Sensory Systems'

R. M. Julien, Eva M. Kavan, and H. W. Elliott

"A Comparison of Methotrimeprazine (Nozinan ${ }^{\oplus}$ ) and Meperidine as Postoperative Analgesic Agents"

M. Minuck

Discussion

Free Afternoon

Friday, July 2

CHAIRMAN: DR. J. WADE

0900-0930 hours "Study of Cataleptogenic Properties of Ketamine in the Rabbit"

L. Authier, A. Sinden, R. Chapados, and P. P. Barry

0930-1000

"Ketamine Anaesthesia for Cardiac Catheterization in Children and Infants"

1000-1015

A. McClish

1015-1030

Discussion

Coffee

1030-1230

Panel: "Anaesthesia and Skeletal Muscle"

Chairman: Dr. J. Wade

Members: Dr. B. Britt

Dr. B. Marshall

Dr. R. Armstrong 